\title{
The Effect of Cinnamon on Cyclical Breast Pain
}

\author{
Najmeh Rajaby Gharaiy, ${ }_{1}^{1}$ Mahnaz Shahnazi, ${ }^{1,}$ Parisa Yavari Kia, ${ }^{1}$ and Yusef Javadzadeh ${ }^{2}$ \\ ${ }^{1}$ Department of Midwifery, Faculty of Nursing and Midwifery, Tabriz University of Medical Sciences, Tabriz, IR Iran \\ ${ }^{2}$ Faculty of Pharmacy, Tabriz University of Medical Sciences, Tabriz, IR Iran \\ "Corresponding author: Mahnaz Shahnazi, Department of Midwifery, Faculty of Nursing and Midwifery, Tabriz University of Medical Sciences, Tabriz, IR Iran. Tel: \\ +98-9155197489, Fax: +98-4114796969, E-mail: Nafisrrrr@yahoo.com
}

Received 2015 January 19; Revised 2015 February 27; Accepted 2015 April 08.

\begin{abstract}
Background: Cyclic mastalgia (breast pain) is one of the most common reasons for referral of women of childbearing age to physicians. Due to the increasing popularity of herbal medicines among women, this study investigates the effect of cinnamon on cyclical breast pain.

objectives: The aim of this study is to determine the effect of cinnamon on cyclical breast pain.

Methods: This was a randomized clinical trial in which 74 women with cyclical breast pain and who met the eligibility criteria were randomly divided into intervention and control groups, based on the four and six random block sampling method. Cinnamon was given to the intervention group and a placebo was given to the control group. The collected data was analyzed by SPSS (statistical package for social science) statistical software (version 14). Chi-square, repeated measures ANOVA (analysis of variance), and independent and paired-t tests were performed.

Results: The mean (SD) values of the patients in the intervention group and the control group were 9.08 (3.56) and 9.45 (2.55), respectively. There was a statistically significant difference between the two groups in the mean scores of pain at the end of the first and second months $(\mathrm{P}<0.001$ and $\mathrm{P}=0.02$ ), meaning the pain intensity at the end of the first and second months were significantly lower in the intervention group than in the control group. The end result of this study showed improvement in both the intervention and control groups: $54.1 \%$ and $2.7 \%$, respectively. Also, an intra-group comparison with ANOVA with repeated measures, the pain mean at the three time periods showed a statistically significant difference between the two groups $(\mathrm{P}<0.001$ and $\mathrm{P}=0.02)$.

Conclusions: Cinnamon can be effective in reducing the intensity of cyclical breast pain in women.

Keywords: Pain, Breast Pain, Cyclical, Cinnamon, Cardiff Chart
\end{abstract}

\section{Background}

Breast pain is a common complaint among women, but has no known etiologic or pathologic reason. According to reports it was observed in approximately $70 \%$ of women, and it is the most common complaint among patients with benign breast lesions (1). There are three main types of breast pain: a) cyclical breast pain, b) non-cyclical breast pain, and c) chest wall pain originating from outside the breast (2). Cyclical breast pain includes pain, tenderness before menstruation (a regular event during the luteal phase) and breast inflation, and lasts at least 5 - 7 days. As the menstrual cycle begins, the symptoms diminish $(3,4)$.

The reasons for this pain have not been completely determined (1). Inflammatory cytokines are considered a contributor, and a previous study demonstrated an interleukin and alpha tumor necrosis factor in patients with breast pain. The findings showed that during the luteal phase the cytokine levels are less in the patients, although the difference was not statistically.significant (5). Estrogen increases or progesterone reductions and impaired estrogen-progesterone balance are also probable causes of breast pain. Breast pain interferes with sexual activity $(48 \%$ of respondents), physical (38\%), social (21\%), professional (8\%), and educational (8\%) activities (2).
Breast pain in women can be reduced through using a proper bra or more efficient painkillers such as acetaminophen or non-steroid anti-inflammatory drugs (NSAIDS) (3). If these practices don't control the pain and interfere with sexual or professional activity, it is recommended that patients try Danazol, Tamoxifen, or Bromocriptine (2, 6-8). However, these drugs are associated with many side effects that limit their use by the public (3).

Non-hormonal treatments include nonsteroidal antiinflammatory gel, iodide, and herbal products like evening primrose oil (EPO) and chasteberry (9). There is considerable discussion about selecting the best method for the primary management of breast pain (10). Dietary changes and herbal supplements such as vitamin E and evening primrose oil are conventional treatments for women with moderate-to-severe cyclical breast pain (4). Evening primrose oil contains a rich source of required essential fatty acid (7 - 14\% gamo lenic acid (GLA)) and inhibits prostaglandin activity $(11,12)$. It is also imported and prepared, so is costly. There are contradictory results on the effects of evening primrose oil and vitamin E on cyclical breast pain $(4,7,11,13-16)$. Two clinical trials in the UK and the Netherlands evaluated evening primrose oil, but placebo effects showed there was no significant effect of using evening primrose oil $(11,16)$. Often, specialists prescribe evening primrose oil as a first-line treatment and 
use the syntactic drugs.for the later stages (2). Three trials provided mean pain scores for primrose oil treatments $(6,11,17)$. In Europe, a multicenter trial by Rabert and colleagues also studied breast pain control.

Cinnamon's drug mechanism is the same as evening primrose oil, so we selected it for use in the present study. Cinnamon is an evergreen tree from the laurel family with a thoroughly resonating perfume. The tree grows in Sri Lanka \& India, and dates back to 2700 BC in China. The plants are used for treatment of respiratory failure and joint pain. Cinnamon is used as a pain reliever, energy provider, anti-spasm treatment, and for reducing the cyclic pain in menstruation (18-20). The essence from the skin contains cinnamaldehyde (55 - 57\%) and eugenol (5 - 18\%). Cinnamaldehyde is the anti-spasm factor of cinnamon, while eugenol may inhibit the biosynthesis of prostaglandin and have effects on inflammation (19). Cinnamon also contains catechins and both A- and B-type procyanidins. Research findings suggest that it is antiinfective and anesthetic. Toxicology and drug studies indicated no danger resulting from using cinnamon in humans (20-23). The procyanidins extracted from cinnamon and berries also contain antioxidant activity (20,24-26).

Women's health strongly affects society since they play major roles as wives and mothers, and are the base of many families (14). Nowadays, more and more women use nonmedicinal and herbal products due to concerns about the adverse effects of pharmaceuticals. Cinnamon could represent a low-cost herbal medicine for women, so we conducted this study to evaluate cinnamon capsules' effects on cyclical breast pain. The study was conducted in the health centers of Mashhad, Iran.

\section{Objectives}

The aim of this study is to determine the effects of cinnamon on cyclical breast pain.

\section{Methods}

This study is a randomized clinical trial carried on 74 women with breast pain who were referred to the governmental health centers of Mashhad, Iran. Inclusion criteria were moderate or severe breast pain, age 18 to 40 years old, a history of breast pain and tenderness during premenstrual syndrome (PMS), moderate or severe pain, pain score greater than 7 on the nominal days breast pain, regular menstrual cycles (23 - 33 days), no recent use of hormone therapy or hormonal contraceptives, lack of sensitivity to cinnamon (itching, hives, digestive problems, etc.), the ability to read and write, and access to a telephone. Exclusion criteria were mental disorders (according to the patient), taking drugs that affected breast pain (antidepressants, digoxin, methyldopa, or spironolactone), being pregnant, or lactating.

To determine the sample size, we used the formula of comparison of two means, following Robert and colleagues' 2004 study (10). Using the numbers in this study (Mean $[\mathrm{M} 1]=17.4$, standard deviation $[\mathrm{SD} 1]=4.8$ ), taking the mean difference of at least $20 \%, \alpha=0.05$, error term $=10 \%$, power $90 \%$, and including $10 \%$ loss, an ideal group size of 37 was calculated. After obtaining permission from the research ethic committee of Tabriz University of Medical Sciences (code: n64.4), we explained the purpose and methodology of the study to the patients who were willing to participate in the study. We asked each potential participant to fill out the Cardiff breast pain chart daily for a month (coinciding with the start of the patient's menstrual cycle). The Cardiff breast pain chart (Figure 1) is composed of thirty squares that participants fill in according to the severity of their pain. If the pain is severe, they fill out the square completely, if the pain is moderate, they fill half the square, and if they had no pain they just put a dot in the square. Patients whose pain score was more than 7 with replacement on the Nominal days breast pain were invited to participate in the cinnamon study. After completing written informed consent, they were asked to fill out questionnaires about their demographic characteristics.

The participants' self-evaluations of mastalgia were recorded daily using the Cardiff chart, and breast pain scores were assessed for a 28-day period after the nominal day of breast pain (NDBP), as follows: Nominal days of breast pain $=[($ total of days non $/$ moderate pain $\times 1)+($ total of days of severe pain $\times 2$ )] $\times 28$ /total no. of days in period with non-missing pain score. The severity of the mastalgia was said to be moderate if the breast pain score was greater than seven and less than fourteen, and severe if the score was greater than fourteen (10). Previous research has established the validity of the Cardiff chart, as it is a standard instrument. Its reliability was evaluated by Fathizadeh, using a Test-Retest method in Iran, and the correlation coefficient was above 0.8 (27).

The sampling method was simple and based on availability. Allocating the participants in the experimental group (the group taking cinnamon) or the control group (the group taking a placebo) was done by the random allocation method using a computerized random number table and the four and six blocking method, with an allocation ratio of 1:1. For allocation concealment, dark and similarly packaged, sequentially numbered packages, labeled from number 1 to 74 , were used. Cinnamon and placebo capsules that were similar in shape, size and color were prepared. The encoded packages included a total of 198 capsules, three capsules per day on all days of the patient's 


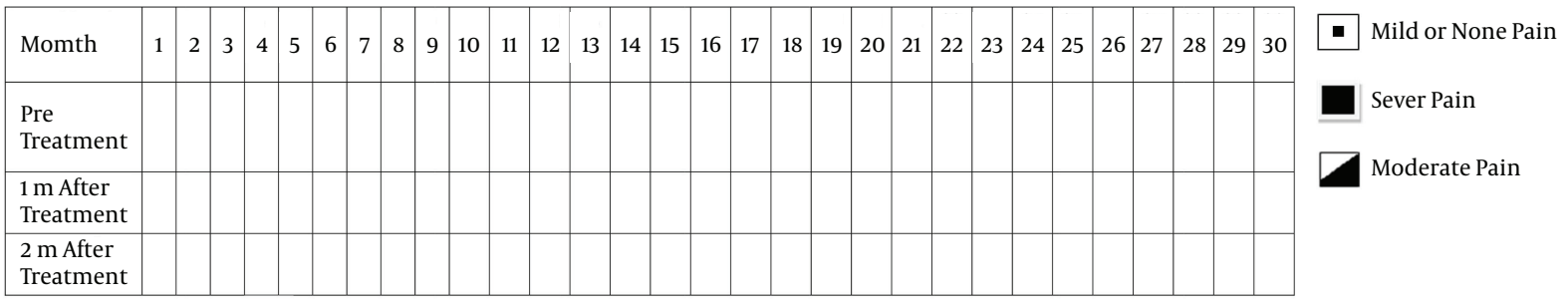

Figure 1. Cardiff Chart ( Daily Pain Chart)

cycle during two months. Allocation was executed by a person uninvolved in the study. For the intervention group, the capsules contained $400 \mathrm{mg}$ of cinnamon, produced in the Tabriz pharmaceutical research center. The placebo capsules were similar to those of the experimental group, without the effective material (cinnamon). The researcher and participants were unaware of the contents of the containers.

Data was collected during three stages: before treatment, 1 month after, and 2 months after treatment. Each participant was given a telephone number to call for help during the treatment, in case they had questions about filling out the questionnaires or about the treatment. After two months, the charts were collected and the final questionnaire was completed through exit interviews with the participants. This questionnaire contains information on treatment satisfaction of participants, and the presence or absence of complications.

The normality of the quantitative variables in each of the groups was reviewed and upheld through descriptive tests. To compare qualitative variables in the two groups a Chi-square $\left(\chi^{2}\right)$ test with accurate P-value was used, and a Chi-square trend test was used to rank the variables. To compare the pain intensity score variables between the two groups before the intervention a t-test was used, and to compare the mean scores for pain intensity after the intervention, the ANCOVA (analysis of covariance) statistical test was used, after adjusting the baseline and accounting for a confounding variable (gravidity). In order to measure the variation in the time of measurements in each group for the severity of pain variable, an analysis of variance with repeated measures was used. The data analysis was performed using SPSS software v.14, and a P value $<0.05$ was considered statistically significant. The clinical trial registration code was IRCT201204146709N11. Data collection lasted 14 months (6.2013 - 8.2014). The data collected in this study followed the normal distribution.

\section{Results}

The study was performed on 74 samples in two groups of 37 people each. During the study there was no loss of sample due to drop out, missing a follow-up, or voluntary exit from the study; every participant continued her cooperation until the end of the research. Demographic and pregnancy characteristics are presented in Tables 1 and 2. There were no significant differences between the two groups in terms of demographics and pregnancy (except gravidity) and they were similar overall.

First pregnancies comprised $24 \%$ and $5 \%$ of pregnancies in the intervention and the control groups, respectively, which showed a statistically significant difference between the two groups ( $P$ value $=0.042$ ); hence, this variable was adjusted as a confounding factor. The results showed that by controlling for pain intensity before the intervention and confounding variables (gravidity), there were statistically significant differences between the mean scores for pain intensity at the end of the first and second month in the two groups, as the mean pain intensity scores at the end of the first and second month in the intervention group was significantly lower than in the control group (Table 3).

Analysis of the data by ANOVA with repeated measures showed that the decrease in the mean scores for pain intensity in three assessed intervals was statistically significant in both groups. As time passes, pain intensity was reduced in both groups; the reduction in the intervention group was more than in the control group. The mean difference score for pain intensity before the intervention and two months after the intervention was statistically significant in both groups (Table 4 ).

$54 \%$ of patients of the intervention group were satisfied with the given treatment, while only $6 \%$ of the control group was satisfied, a significant difference ( $\mathrm{P}$ value $<0.001$ ). In terms of frequency of drug use, the majority of patients in both groups did not need extra medication, so there was no significant difference between the two groups ( $\mathrm{P}$ value $=0.007$ ). Overall $59 \%$ of participants 
Table 1. Demographic Characteristics of the Two Groups

\begin{tabular}{|c|c|c|c|c|}
\hline & Intervention Group, N = 37 & Control Group, N= 37 & Total N= 74 & Statistical Indicators \\
\hline Age, y, Mean (SD) & $26.2(5.58)$ & $25.76(4.65)$ & & $\mathrm{T}^{\mathrm{a}}=0.44, \mathrm{df}=98, \mathrm{P}=0.65$ \\
\hline Education, No. (\%) & & & & $\chi^{2 \mathrm{~b}}=2.37, \mathrm{df}=3, \mathrm{P}=0.49$ \\
\hline Elementary & $7(18)$ & $3(8.1)$ & $10(13.5)$ & \\
\hline Middle School & $6(16.2)$ & $6(16.2)$ & $12(16.2)$ & \\
\hline High School & $15(40.5)$ & $20(36)$ & $35(47.3)$ & \\
\hline University & $9(24.3)$ & $8(21.6)$ & $17(23)$ & \\
\hline Total & $37(100)$ & $37(100)$ & $74(100)$ & \\
\hline Job Status, No. (\%) & & & & $\chi^{2}=0.094, \mathrm{df}=2, \mathrm{P}=0.95$ \\
\hline House keeper & $59(74.8)$ & $30(81.1)$ & $59(79.7)$ & \\
\hline Employed outside home & $1(2.7)$ & $1(2.7)$ & $2(2.7)$ & \\
\hline Working at home & $7(18.9)$ & $6(16.2)$ & $13(17.6)$ & \\
\hline Total & $37(100)$ & $37(100)$ & $74(100)$ & \\
\hline Income, No. (\%) & & & & $\chi^{2}=15.11, \mathrm{df}=2, \mathrm{P}=0.47$ \\
\hline Earn equal pay & $12(32.4)$ & $14(37.8)$ & $26(35.1)$ & \\
\hline Earn less pay & $19(51.4)$ & $14(37.8)$ & $33(44.6)$ & \\
\hline Earn more pay & $6(16.2)$ & $9(24.3)$ & $15(20.3)$ & \\
\hline Total & $37(100)$ & $37(100)$ & $74(100)$ & \\
\hline Marital Status, No. (\%) & & & & $\chi^{2}=8.68, \mathrm{df}=3, \mathrm{P}=0.034$ \\
\hline Single & $14(37.8)$ & $21(56.8)$ & $35(47.3)$ & \\
\hline Married & $20(54.1)$ & $11(29.7)$ & $31(41.9)$ & \\
\hline Devote & $1(2.7)$ & $5(13.5)$ & $6(8.1)$ & \\
\hline Widow & $2(5.4)$ & 0 & $2(2.7)$ & \\
\hline Total & $37(100)$ & $37(100)$ & $74(100)$ & \\
\hline
\end{tabular}

${ }^{\mathrm{a}}$ Independent sample T-test.

${ }^{\mathrm{b}}$ Trend $\chi^{2}$.

in the intervention group and $2.7 \%$ of those in the control group were satisfied with their treatments. All participants in the study had adhered to recommendations for changes in their diet and lifestyle. There were no adverse effects due to the treatment.

\section{Discussion}

No previous clinical trial has addressed the effect of cinnamon on cyclical breast pain severity. According to the findings of the present study, the mean scores of cyclical breast pain severity of women decreased during 2 months of using cinnamon capsules and placebos, but more in the intervention group than in the control group. According to the hypothesis, cinnamon capsules can reduce cyclical breast pain. Therefore, the hypothesis was confirmed. Results of a study in Iran by Akhavan Amjady on the effect of cinnamon on primary dysmenorrhea showed statistically significant differences between the intervention and control groups in treatment of pain severity (28). The results of this study are consistent with the present study. Alvandi et al. (2011) conducted a similar study on 100 women with cyclical breast pain, and Perotti et al. likewise studied 85 women complaining of cyclical breast pain in the United States. Both studies showed that vitamin E and evening primrose oil may be effective in breast pain reduction, either separately or in combination $(13,14)$.

The present study's results may support the idea that determining the appropriate treatment approach for patients with cyclical breast pain needs further discussion. It is difficult to control some of the contributing factors to breast pain severity, such as mental properties and personal differences. Moreover, the threshold of pain differs from person to person. The patients in this study were 
Table 2. Pregnancy Characteristics of the Two Groups

\begin{tabular}{|c|c|c|c|c|}
\hline & Intervention Group, $\mathrm{N}=\mathbf{5 0}, \mathrm{No}$. (\%) & Control Group, N = 50, No. (\%) & Total, $\mathbf{N}=100$, No. $(\%)$ & Statistical Indicators \\
\hline Gravidity & & & & $\chi^{2}=9.88, \mathrm{df}=4, \mathrm{P}=0.042$ \\
\hline 1 & $19(51.4)$ & $29(78.4)$ & $48(64.9)$ & \\
\hline 2 & $9(24.3)$ & $2(5.4)$ & $11(14.9)$ & \\
\hline 3 & $4(10.8)$ & $3(8.1)$ & $7(9.5)$ & \\
\hline$\geq 3$ & $2(5.4)$ & 0 & $5(6.8)$ & \\
\hline Total & $3(8.1)$ & $29(78.4)$ & $3(4.1)$ & \\
\hline Contraceptive method & & & & $\chi^{2}=3.03, \mathrm{df}=4, \mathrm{P}=0.55$ \\
\hline Without method & $21(56.8)$ & $25(67.6)$ & $46(62.2)$ & \\
\hline Condom & $9(24.3)$ & $6(16.2)$ & $15(20.3)$ & \\
\hline Withdrawal & $5(13.5)$ & $6(16.2)$ & $11(14.9)$ & \\
\hline IUD & $1(2.7)$ & 0 & $1(1.4)$ & \\
\hline $\mathrm{Tl}$ & $1(2.7)$ & 0 & $1(1.4)$ & \\
\hline Total & $37(100)$ & $37(100)$ & $100(100)$ & \\
\hline \multirow[t]{2}{*}{ Menark } & & & & $\mathrm{t}^{\mathrm{a}}=-0.06, \mathrm{df}=72, \mathrm{P}=0.95$ \\
\hline & $11.46(2.09)$ & $11.67(1.71)$ & $-0.02(0.0,91.08)$ & \\
\hline Total & $37(100)$ & $37(100)$ & $74(100)$ & \\
\hline
\end{tabular}

${ }^{\mathrm{a}}$ Independent sample T-test.

Table 3. Comparison Mean Scores for Pain Intensity Before and the End of First and Second Months After the Intervention

\begin{tabular}{|c|c|c|c|c|}
\hline & Interventio Group Mean (SD), N = 37 & Control Group Mean (SD), N = 37 & MD $^{a}($ CI95\%) & Statistical Indicators \\
\hline Before intervention & $10.59(2.22)$ & $9.78(2.02)$ & $0.81(-0.17,17.79)$ & $\mathrm{T}^{\mathrm{b}}=1.63, \mathrm{df}=72, \mathrm{P}=0.1$ \\
\hline After 1 month & $8.27(2.34)$ & $9.29(0.98)$ & $-1.02(-2.06,0.01)$ & $\mathrm{F}^{\mathrm{C}}=139.11, \mathrm{df}=1, \mathrm{P}=0.00$ \\
\hline After 2 months & $9.08(3.56)$ & $9.45(2.55)$ & $-0.37(-1.81,-1.05)$ & $\mathrm{F}=75.78, \mathrm{df}=1, \mathrm{P}=0.00$ \\
\hline
\end{tabular}

${ }^{\text {a }}$ Mean Difference (Confidence Interval 95\%).

b Independent sample T-test.

${ }^{\mathrm{c}}$ ANCOVA.

Table 4. Comparison of Mean Difference of Total Scores of Pain Intensity at Three Intervals

\begin{tabular}{|c|c|c|c|c|}
\hline & Intervention Group, Mean(SD) & Control Group, Mean(SD) & $\mathrm{MD}^{\mathrm{a}}(\mathrm{CI95} \%)$ & Statistical Indicators \\
\hline 1 Month after vs. before intervention & $-2.32(1.61)$ & $-0.48(0.98)$ & $-1.83(-2.45,-1.21)$ & $\mathrm{T}^{\mathrm{b}}=-5.89, \mathrm{df}=72, \mathrm{P}=0.000$ \\
\hline 2 Months after vs. before intervention & $-1.51(2.61)$ & $-0.32(1.58)$ & $-1.18(-2.15,-0.18)$ & $\mathrm{T}=-2.37, \mathrm{df}=72, \mathrm{P}=0.02$ \\
\hline ANOVA with repeated measures & $\mathrm{F}=34.78, \mathrm{df}=73, \mathrm{P}<0.001$ & $\mathrm{~F}=5.61, \mathrm{df}=73, \mathrm{P}=0.02$ & & \\
\hline
\end{tabular}

a Mean Difference (Confidence Interval 95\%).

${ }^{\mathrm{b}}$ Independent sample T-test.

assessed in detail before they participated, to ensure that they did not have any malignant diseases. They were also recommended to use proper diet and low-xanthine. Medical treatment of cyclical breast pain includes chemical drugs with extensive side effects, which are often not considered useful drugs. It is believed that herbal medicines are more useful to disease treatment (29). The strengths of this study are the randomized selection of samples and being double-blinded. The limitation of this study was the short time frame: due to time constraints the follow-up period was limited, and the sampling was done by a researcher. 


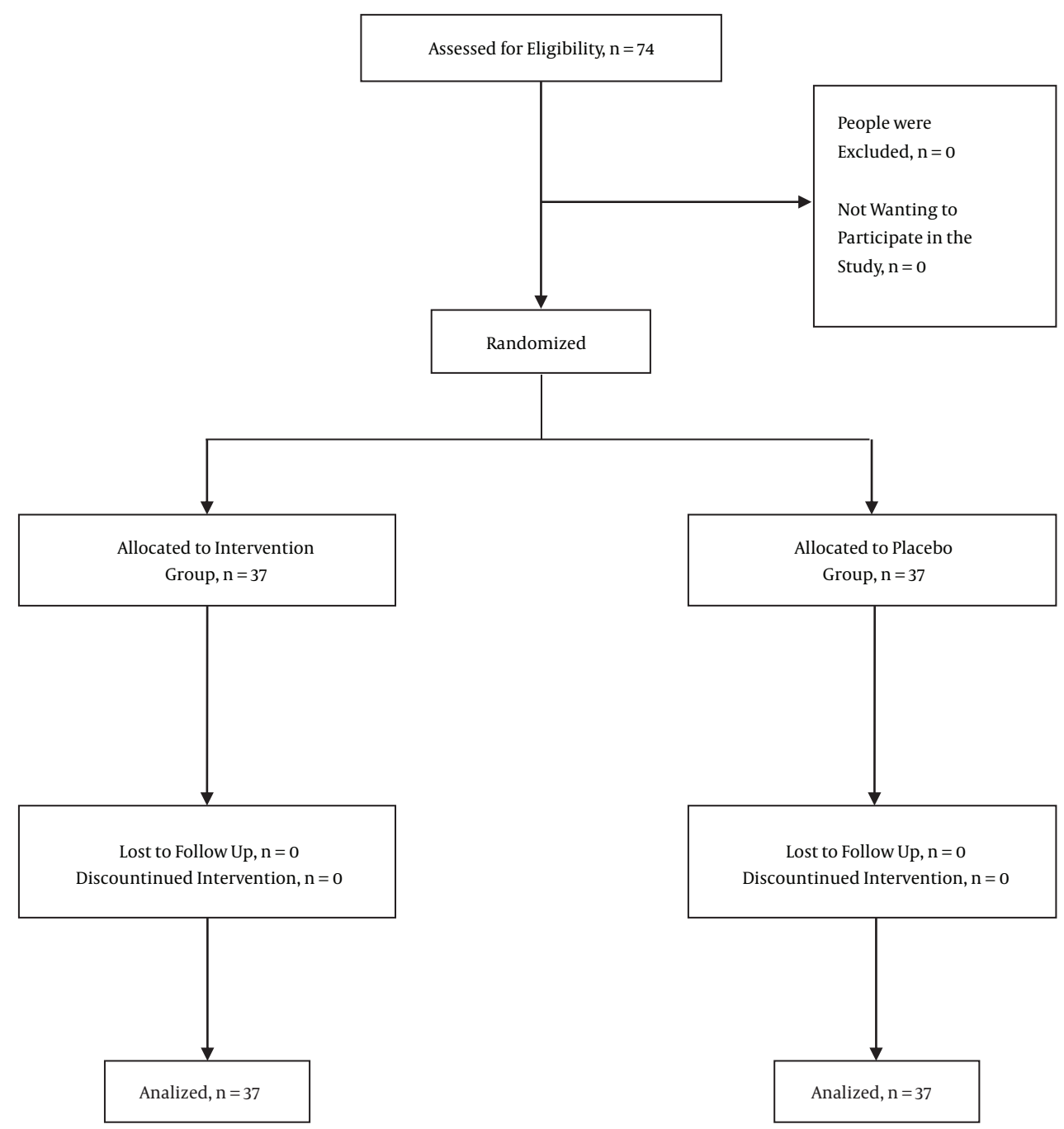

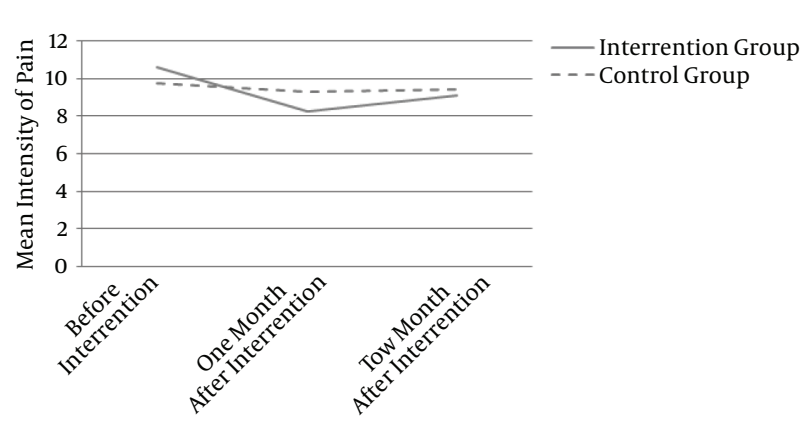

$\overline{\text { Figure 3. Comparison of Changes in Pain Scores Between the Two Groups at Three }}$ Intervals

\section{Acknowledgments}

The authors appreciate the research deputy of Tabriz University of Medical Sciences for financial support, and our colleagues who helped us collect data for this study.

\section{Footnotes}

Authors' Contribution: Study concept and design: Mahnaz Shahnazi, Najmeh Rajaby Gharaiy, Yusef Javadzadeh, and Parisa Yavari kia; analysis and interpretation of data: Mahnaz Shahnazi, Najmeh Rajaby Gharaiy; drafting of the manuscript: Najmeh Rajaby Gharaiy; critical revision of the manuscript for important intellectual content: Mahnaz Shahnazi, Yusef Javadzadeh, Parisa Yavari Kia, and Na- 
jmeh Rajaby Gharaiy; statistical analysis: Mahnaz Shahnazi and Najmeh Rajaby Gharaiy.

Financial Disclosure: There is no financial disclosure. Funding/Support: Research deputy of Tabriz University of Medical Sciences.

\section{References}

1. Davies EL, Gateley CA, Miers M, Mansel RE. The long-term course of mastalgia. J R Soc Med. 1998;91(9):462-4. [PubMed: 9849515].

2. Berek J. Berek and Novak gynecology. 15 ed. Philadelphia: Lippincott Williams and Wilkins; 2007.

3. Smith RL, Pruthi S, Fitzpatrick LA. Evaluation and management of breast pain. Mayo Clin Proc. 2004;79(3):353-72. doi: 10.4065/79.3.353. [PubMed: 15008609].

4. Parsay S, Olfati F, Nahidi S. Therapeutic effects of vitamin E on cyclic mastalgia. Breast J. 2009;15(5):510-4. doi: 10.1111/j.15244741.2009.00768.x. [PubMed: 19614907].

5. Ramakrishnan R, Werbeck J, Khurana KK, Khan SA. Expression of interleukin-6 and tumor necrosis factor alpha and histopathologic findings in painful and nonpainful breast tissue. Breast $J$. 2003;9(2):91-7. [PubMed: 12603381].

6. Srivastava A, Mansel RE, Arvind N, Prasad K, Dhar A, Chabra A. Evidence-based management of Mastalgia: a metaanalysis of randomised trials. Breast. 2007;16(5):503-12. doi 10.1016/j.breast.2007.03.003. [PubMed:17509880].

7. Rosolowich V, Saettler E, Szuck B, Lea RH, Lévesque P, Weisberg F, et al. Mastalgie. JOGC. 2006;28(1):61-71. doi:10.1016/s1701-2163(16)32028-x.

8. Gateley CA, Maddox PR, Mansel RE, Hughes LE. Mastalgia refractory to drug treatment. Br J Surg. 1990;77(10):1110-2. [PubMed: 2224458].

9. Halaska M, Beles P, Gorkow C, Sieder C. Treatment of cyclical mastalgia with a solution containing a Vitex agnus castus extract: results of a placebo-controlled double-blind study. Breast. 1999;8(4):175-81. doi: 10.1054/brst.1999.0039. [PubMed: 14731436].

10. Mansel RE, Goyal A, Preece P, Leinster S, Maddox PR, Gateley C, et al. European randomized, multicenter study of goserelin (Zoladex) in the management of mastalgia. Am J Obstet Gynecol. 2004;191(6):1942-9. doi:10.1016/j.ajog.2004.06.100. [PubMed: 15592276].

11. Blommers J, de Lange-De Klerk ES, Kuik DJ, Bezemer PD, Meijer S. Evening primrose oil and fish oil for severe chronic mastalgia: a randomized, double-blind, controlled trial. Am J Obstet Gynecol. 2002;187(5):1389-94. [PubMed: 12439536].

12. Horrobin DF, Manku MS. Premenstrual syndrome and premenstrual breast pain (cyclical mastalgia): disorders of essential fatty acid (EFA) metabolism. Prostaglandins Leukot Essent Fatty Acids. 1989;37(4):25561. [PubMed: 2682673].

13. Alvandi Poor M, Tayebi P, AlizadehNavaee R, Khodabakhshi H. Comparison of Evening Primrose With vitamin E in the treatment of cyclic mastalgia. Babol Univ Med Sci J. 2010;13(2):7-11.

14. Pruthi S, Wahner-Roedler DL, Torkelson CJ, Cha SS, Thicke LS, Hazelton $\mathrm{JH}$, et al. Vitamin $\mathrm{E}$ and evening primrose oil for management of cyclical mastalgia: a randomized pilot study. Altern Med Rev. 2010;15(1):5967. [PubMed: 20359269].

15. London RS, Sundaram GS, Murphy L, Manimekalai S, Reynolds M, Goldstein PJ. The effect of vitamin E on mammary dysplasia: a doubleblind study. Obstet Gynecol. 1985;65(1):104-6. [PubMed: 3880876].
16. Goyal A, Mansel RE, Efamast Study Group . A randomized multicenter study of gamolenic acid (Efamast) with and without antioxidant vitamins and minerals in the management of mastalgia. Breast J. 2005;11(1):41-7. doi: 10.1111/j.1075-122X.2005.21492.x. [PubMed: 15647077].

17. Sharma N, Gupta A, Jha PK, Rajput P. Mastalgia cured! Randomized trial comparing centchroman to evening primrose oil. Breast J. 2012;18(5):509-10. doi: 10.1111/j.1524-4741.2012.01288.x. [PubMed: 22892074].

18. Yeh HF, Luo CY, Lin CY, Cheng SS, Hsu YR, Chang ST. Methods for thermal stability enhancement of leaf essential oils and their main constituents from indigenous cinnamon (Cinnamomum osmophloeum). J Agric Food Chem. 2013;61(26):6293-8. doi: 10.1021/jf401536y. [PubMed: 23738884].

19. Rao PV, Gan SH.Cinnamon: a multifaceted medicinal plant. Evid Based Complement Alternat Med. 2014;2014:642942. doi:10.1155/2014/642942. [PubMed: 24817901].

20. Marongiu B, Piras A, Porcedda S, Tuveri E, Sanjust E, Meli M, et al. Supercritical $\mathrm{CO} 2$ extract of Cinnamomum zeylanicum: chemical characterization and antityrosinase activity. J Agric Food Chem. 2007;55(24):10022-7. doi: 10.1021/jf071938f. [PubMed: 17966976].

21. Chou ST, Chang WL, Chang CT, Hsu SL, Lin YC, Shih Y. Cinnamomum cassia essential oil inhibits alpha-MSH-induced melanin production and oxidative stress in murine B16 melanoma cells. Int J Mol Sci. 2013;14(9):19186-201. doi: 10.3390/ijms140919186. [PubMed: 24051402].

22. Tanaka T, Matsuo Y, Yamada Y, Kouno I. Structure of polymeric polyphenols of cinnamon bark deduced from condensation products of cinnamaldehyde with catechin and procyanidins. J Agric Food Chem. 2008;56(14):5864-70. doi: 10.1021/jf800921r. [PubMed: 18558701].

23. Anderson RA, Broadhurst CL, Polansky MM, Schmidt WF, Khan A, Flanagan VP, et al. Isolation and characterization of polyphenol typeA polymers from cinnamon with insulin-like biological activity. $J$ Agric Food Chem. 2004;52(1):65-70. doi: 10.1021/jf034916b. [PubMed: 14709014].

24. Maatta-Riihinen KR, Kahkonen MP, Torronen AR, Heinonen IM. Catechins and procyanidins in berries of vaccinium species and their antioxidant activity. J Agric Food Chem. 2005;53(22):8485-91. doi: 10.1021/jf050408l. [PubMed: 16248542].

25. Tung YT, Chua MT, Wang SY, Chang ST. Anti-inflammation activities of essential oil and its constituents from indigenous cinnamon (Cinnamomum osmophloeum) twigs. Bioresour Technol. 2008;99(9):3908-13. doi: 10.1016/j.biortech.2007.07.050. [PubMed: 17826984].

26. Peng X, Cheng KW, Ma J, Chen B, Ho CT, Lo C, et al. Cinnamon bark proanthocyanidins as reactive carbonyl scavengers to prevent the formation of advanced glycation endproducts. J Agric Food Chem. 2008;56(6):1907-11. doi: 10.1021/jf073065v. [PubMed: 18284204].

27. Fathizadeh N, Takfallah L, Ehsanpour S, Namnabati M, Askari S. Effects of evening primrose oil and vitamin $\mathrm{E}$ on the severity of periodical breast pain [in Persian]. IJNMR. 2009;13(3).

28. Akhavan Amjadi M, Mojab F, Shhbazzadgan S. Effect of cinnamon on primary dysmenorrhea and associated symptoms [Persian].J Ardabil Univ Med Sci. 2009;8(3):204-9.

29. Ryan KJ, Berkowitz RS, Barbieri RL, Dunaif A. Kistners gyneocology and women health. 7 ed. Edinburgh: Mosby;1999. pp. 23-5. 